\title{
ETIOLOGIA E SENSIBILIDADE ANTIMICROBIANA NA INFECÇÃO DO TRATO URINÁRIO EM CÃES NA REGIÃO DE BOTUCATU - SP
}

\author{
HÉLIO LANGONI ${ }^{1}$ \\ ARISTEU VIEIRA DA SILVA ${ }^{2}$ \\ SIMONE BALDINI ${ }^{3}$ \\ VALÉRIA S.F. HOMEM ${ }^{2}$ \\ FERNANDO J.P. LISTONI ${ }^{4}$ \\ MARIA JOSÉ B. DE CAMARGO ${ }^{5}$.
}

\begin{abstract}
LANGONI, H; Da SILVA, A.V; BALDINI, S; HOMEM, V.S.F; LISTONI, F.J.P; CAMARGO, M.J.B. Etiologia e sensibilidade antimicrobiana na infecção do trato urinário em cães na região de Botucatu - SP. Semina: Ci. Agr., Londrina, v.17, n.1, p.25-29, mar. 1996.

RESUMO: Foram examinadas 240 amostras de urina de cães de ambos os sexos e idade entre 1 e 14 anos, cultivadas em meios de Ágar-sangue e Levine. Mostraram-se positivas 133 (55,4\%) amostras, e os microrganismos mais isolados foram: Escherichia coli (40,1\%), Streptococcus canis (17,7\%), Proteus mirabilis (14,6\%) e Staphylococcus aureus (11,5\%). Escherichia coli mostrou-se sensível a gentamicina e ao cloranfenicol; a ampicilina teve boa ação contra Streptococcus canis, enquanto as amostras de Proteus foram mais sensíveis a gentamicina e ampicilina; o cloranfenicol e a gentamicina foram as drogas mais eficientes contra o Staphylococcus aureus.
\end{abstract}

PALAVRAS-CHAVE: cão, infecção do trato urinário, microbiologia.

\section{INTRODUÇÃO}

A infecção do trato urinário (ITU) é comum na espécie canina, chegando a acometer $14 \%$ de todos os cães em algum momento de suas vidas (LING, 1984). A causa mais comum desse tipo de patologia é a invasão do trato urinário por bactérias (BUSH, 1976), mas também podem ocorrer infecções por vírus, algas e Mycoplasma spp (JANG et al., 1984), além de processos primariamente esteréis, tais como a urolítiase e a neoplasia do trato urinário.

A ITU desenvolve-se quando existe alguma alteração das defesas do trato urinário que permita a entrada e a proliferação dos microrganismos. Um dos principais mecanismos de defesa do trato urinário é a própria eliminação da urina vesical, que funciona como uma lavagem de todo o trato urinário inferior; além disso a mucosa da bexiga urinária possui propriedades antibacterianas e o próprio $\mathrm{pH}$ ácido da urina canina impedem a migração, a aderência e a proliferação bacteriana (OXENFORD et al., 1984). As bactérias atingem o trato urinário pelas mais diversas vias, inclusive a hematógena, a linfática ou por extensão de infecções em tecidos adjacentes. No entanto o mais comum é a via ascendente (BUSH, 1976).

Diversos autores concordam que as bactérias Gramnegativas são as mais freqüentes nas infecções urinárias em cães, com especial atenção para a Escherichia coli

\footnotetext{
${ }^{1}$ Professor do Departamento de Higiene Veterinária e Saúde Pública da FMVZ-UNESP- Distrito de Rubião Júnior - Botucatu - SP - CEP 18650 -000 - TEL. 212121 (ramal 2270/2191).

${ }_{3}^{2}$ Alunos do curso de Medicina Veterinária da FMVZ - UNESP -Botucatu.

${ }^{3}$ Médica Veterinária Residente do Departamento de Higiene Veterinária e Saúde Pública - Disciplina de Zoonoses - FMVZ - UNESP - Botucatu.

4,5 Técnico e Auxiliar de Laboratório do Departamento de Higiene Veterinária e Saúde Pública - FMVZ - UNESP - Botucatu.
} 
e Proteus sp (BUSH, 1976; OXENFORD et al.,1984; PERSON et al, 1989 ; COTARD, 1990). Os microrganismos Gram-positivos mais comuns, segundo os mesmos autores, são os Staphylococcus sp e os Streptococcus sp, podendo vir a concorrer com até 25\% de todas as infecções. Finalmente, o isolamento de diversas espécies bacterianas em uma mesma infecção é menos comum, variando de 7,9 a $18 \%$ de todos os casos relatados (LING, 1984).

Em vista de sua etiologia predominantemente bacteriana, ganha importância nas infecções urinárias caninas, o cultivo de amostras de urina. Esta não tem por objetivo apenas identificar os patógenos envolvidos em uma ITU, mas também de determinar sua sensibilidade a agentes antimicrobianos, orientando o clínico para uma terapêutica adequada (CHEW \& DIBARTOLA, 1992).

Com o objetivo de determinar a prevalência dos microrganismos causadores de infecções urinárias em cães na região de Botucatu - SP, assim como a sua sensibilidade aos agentes antimicrobianos, examinouse microbiologicamente a urina de cães com suspeitas de ITU, enviadas ao Laboratório de Diagnóstico Microbiológico do Hospital Veterinário (SDM-HV) da FMVZ, UNESP, Botucatu, SP.

\section{MATERIAL E MÉTODOS}

Foram examinadas 240 amostras de urina de cães de ambos os sexos, com idades entre 1 e 14 anos, com suspeita de nefropatia, enviadas ao SDM-HV durante o período de 1985 à 1991. As mesmas foram colhidas através de cateterismo vesical, após antissepsia da região genital com Merthiolate 3\%, utilizando-se para tanto seringa estéril adaptada à sonda, enviando-se o material para os procedimentos microbiológicos imediatamente após sua obtenção.

De cada amostra foi semeado $0,1 \mathrm{ml}$ em meios de ÁGAR-SANGUE e LEVINE, espalhando-se por toda a placa. Após 24,48 e 72 horas de incubação a 37símbolo 176 If "Symbol"C procedeu-se à observação das características morfológicas das colônias. A partir destas colônias foi feito repique em meio de ÁGAR-CÉREBROCORAÇÃO para realização de antibiograma segundo o método de KIRBY-BAUER (BAUER et al., 1966) e posterior taxonomia, de acordo com KRIEG \& HOLT (1984). Foi considerada como amostra positiva aquela onde se obtinha o isolamento de mais de 100 colônias (1000 colônias/ml).

\section{RESULTADOS}

Obtiveram-se $133(55,4 \%)$ amostras positivas, sendo $105(78,9 \%)$ com o isolamento de apenas um microrganismo e $28(21,1 \%)$ de dois ou mais agentes em associação.

Os resultados dos exames microbiológicos podem ser apreciados nas Tabelas 1 e 2 , enquanto que os resultados dos antibiogramas são vistos na Tabela 3 .

Os resultados foram avaliados estatisticamente através do teste do $\chi^{2}$ ou do teste Exato de Fisher (ZAR, 1984) para comparar as proporções de ocorrência das bactérias entre machos e fêmeas ; as diferenças foram consideradas significativas quando $p<0,05$.

TABELA 1 - Resultado do exame microbiológico de amostras de urina de cães com infecção urinária, examinadas pelo SDM-HV, FMVZ, UNESP, Botucatu, SP, durante o período de 1985 a 1991.

\begin{tabular}{|c|c|c|c|c|c|c|c|}
\hline \multirow{2}{*}{ MICRORGANISMO } & \multicolumn{2}{|c|}{ MACHOS } & \multicolumn{2}{|c|}{ FÊMEAS } & \multirow[b]{2}{*}{$\mathbf{P}$} & \multirow{2}{*}{$\begin{array}{l}\text { TOTAL } \\
\text { № }\end{array}$} & \multirow[b]{2}{*}{$\%$} \\
\hline & № & $\%$ & No & $\%$ & & & \\
\hline Escherichia coli não hemolítica & 49 & 31,2 & 16 & 45,7 & $>10$ & 65 & 33,8 \\
\hline Escherichia coli b-hemolítica & 11 & 7,0 & 1 & 2,9 & $>0,2$ & 12 & 6,3 \\
\hline Streptococcus canis & 31 & 19,7 & 3 & 8,6 & $<0,05$ & 34 & 17,7 \\
\hline Proteus mirabilis & 24 & 15,3 & 4 & 11,4 & $>0,5$ & 28 & 14,6 \\
\hline Staphylococcus aureus & 17 & 10,8 & 5 & 14,3 & $>0,5$ & 22 & 11,5 \\
\hline Staphylococcus epidermidis & 14 & 8,9 & 3 & 8,6 & $>0,5$ & 17 & 8,9 \\
\hline Corynebacterium $\mathrm{sp}$ & 5 & 3,2 & 0 & 0 & $<0,001$ & 5 & 2,6 \\
\hline Klebsiella pneumoniae & 3 & 1,9 & 2 & 5,7 & $>0,5$ & 5 & 2,6 \\
\hline Pseudomonas aeruginosa & 1 & 0,6 & 1 & 2,9 & - & 2 & 1,0 \\
\hline Pasteurella multocida & 1 & 0,6 & 0 & 0 & - & 1 & 0,5 \\
\hline Candida albicans & 1 & 0,6 & 0 & 0 & - & 1 & 0,5 \\
\hline
\end{tabular}


TABELA 2 - Microrganismos isolados em associação a partir de amostras de urina de cães com infecção urinária, examinadas pelo Serviço de Diagnóstico Microbiológico do Hospital Veterinário da FMVZ, UNESP, Botucatu, SP.

MICRORGANISMOS EM ASSOCIAÇÃO

Escherichia coli + Streptococcus canis

Escherichia coli + Proteus mirabilis

Staphylococcus aureus + Streptococcus canis

Staphylococcus epidermidis + Streptococcus canis

Staphylococcus epidermidis + Proteus mirabiblis

Klebsiella pneumoniae + Proteus mirabilis

Klebsiella pneumoniae + Escherichia coli

Streptococcus canis + Candida albicans

Streptococcus canis + Proteus mirabilis

Escherichia coli + Corynebacterium sp

Staphylococcus aureus + Escherichia coli

Proteus mirabilis + Klebsiella pneumoniae + Escherichia coli

Proteus mirabilis + Escherichia coli + Pseudomonas aeruginosa

Proteus mirabilis + Escherichia coli + Streptococcus canis

TOTAL
NÚMERO DE ASSOCIAÇÕES
$\%$

21,4

17,9

10,6

10,7

7,1

3,6

3,6

3,6

3,6

3,6

3,6

3, 6

3, 6

3, 6

28

100,0

TABELA 3 - Resultados em porcentagem, da sensibilidade bacteriana frente aos diferentes antimicrobianos, de microrganismos isolados de cães com infecção urinária.

\begin{tabular}{lllllllll}
\hline & \multicolumn{1}{c}{ DROGAS } \\
\cline { 2 - 9 } MICRORGANISMO & CO & NT & TT & NC & PN & AP & GN & S \\
\hline Escherichia coli não hemolítica & 36,6 & 45,0 & 10,3 & 14,3 & NT & 13,7 & 49,1 & 13,3 \\
Escherichia coli b-hemolítica & 37,5 & 50,0 & 12,5 & 0 & NT & 42,8 & 57,1 & 33,3 \\
Streptococcus canis & 50,0 & 65,5 & 17,8 & NT & 40 & 56,5 & 41,0 & 0 \\
Proteus mirabilis & 20,8 & 21,4 & 11,5 & 0 & NT & 41,2 & 69,2 & 7,0 \\
Staphylococcus aureus & 94,7 & 95,2 & 57,8 & 40,0 & 14,3 & 26,3 & 75,0 & 0 \\
Staphylococcus epidermidis & 58,3 & 66,7 & 41,7 & 33,3 & 0 & 45,4 & 54,5 & 0 \\
Corynebacterium sp & 25,0 & 0 & 25,0 & NT & 33,3 & 50,0 & 50,0 & 0 \\
Klebsiella pneumoniae & 40,0 & 20,0 & 20,0 & NT & NT & 25,0 & 20,0 & 0 \\
Pseudomonas aeruginosa & 0 & 0 & 0 & 25 & NT & 50,0 & 50,0 & NT \\
\hline
\end{tabular}

Onde: $\mathrm{CO}=$ Cloranfenicol, $\mathrm{NT}=$ Nitrofurantoína, $\mathrm{TT}=$ Tetraciclina, $\mathrm{NE}=$ Neomicina $, \mathrm{PN}=\mathrm{Penicilina}, \mathrm{AP}=\mathrm{Ampicilina}, \mathrm{GN}=\mathrm{Gentamicina}, \mathrm{S}=\mathrm{Sulfa}$, NT = Não Testado. 


\section{DISCUSSÃO}

Diversos autores são unânimes ao afirmar a maior prevalência da Escherichia coli e Proteus spp nas infecções urinárias do cão (BUSH, 1976 ; PERSON et al, 1989), no que o nosso trabalho concorda, já que os dois gêneros representam $54,7 \%$ dos microrganismos isolados e $97,7 \%$ de todas as bactérias Gram-negativas. As espécies de Staphylococcus e Streptococcus são, após os microrganismos Gram-negativos, as bactérias mais freqüentes nas amostras analisadas, o que vem também ao encontro dos trabalhos citados. Isto confirma como fonte de bactérias a região perianal e perigenital, e a via de entrada para o aparelho urinário a ascendente, como já apontava BUSH (1976).

Anatomicamente as fêmeas são naturalmente mais susceptíveis à invasão bacteriana do trato urinário. BUSH (1976) reforça esta idéia para as infecções urinárias na espécie humana, mas PERSON et al. (1989) não apontam diferenças significativas entre os sexos para as uroculturas positivas. No presente estudo a análise estatística também mostrou que não existiu, para a maioria das espécies bacterianas, diferença de isolamento entre machos e fêmeas, exceção feita ao Streptococcus canis e Corynebacterium $\mathrm{sp}$, mais isolados em machos do que em fêmeas.

PERSON et al. (1989) demonstraram a existência de uma influência da idade sobre o índice de bacteriúrias significativas, com 41,4 a $51,5 \%$ dos cães afetados (fêmeas e machos, respectivamente) tendo mais de sete anos de idade. Nossos resultados apontam que $65,9 \%$ das culturas positivas concentramse na faixa etária até os seis anos de idade.
Como demonstra a Tabela 3, a gentamicina, seguida da nitrofurantoína e do cloranfenicol foram as drogas mais ativas para Escherichia coli. A gentamicina e a ampicilina foram as drogas mais efetivas nos antibiogramas de Proteus mirabilis. LING et al. (1984) obtiveram $100 \%$ de cura nos casos de infecção urinária por Proteus sp tratados com ampicilina via oral. Nosso trabalho demonstra que, para amostras de Staphylococcus aureus, as drogas mais indicadas seriam a nitrofurantoína, a gentamicina e o cloranfenicol. A utilização do cloranfenicol por LING \& RUBY (1978), em infecções urinárias devidas a S.aureus, revelou taxas de cura de $84 \%$. As amostras de Streptococcus canis mostraram-se mais sensíveis à ação da nitrofurantoína e ampicilina.

As infecções do trato urinário em geral são restritas à bexiga e à uretra, mas podem atingir o rim, gerando quadros agudos de pielonefrite que acabam por levar à falência renal (BUSH, 1976). Prostatite, neoplasia vesical, discoespondilite e septicemia também podem ser resultado de uma ITU (BROWN \& BARSANT, 1992). Disto depreende-se a importância do exame microbiológico da urina, não só na determinação do agente etiológico, mas também para estabelecer as alternativas terapêuticas mais adequadas para cada caso, evitando-se assim as infecções recorrentes e suas possíveis complicações.

\section{AGRADECIMENTOS}

Ao Prof.Dr. Paulo Roberto Curi, da FMVZ-UNESPBotucatu, pelo assessoramento na análise estatística.

LANGONI,H; DA SILVA, A.V; BALDINI, S; HOMEM, V.S.F; LISTONI, F.J.P; CAMARGO, M.J.B. Etiology and antimicrobial sensibility in the dog's urinary tract infection in Botucatu - SP. Semina : Ci. Agr., Londrina, v.17, n.1, p.25-29, mar. 1996.

ABSTRACT: 240 samples of urine male and dogs ranging from 1 to 14 years old were inspected and cultivated in media such as blood agar and Levine. 133 samples (55,4\%) showed to be positive and the most isolated microrganisms were: Esoherichia coli $(40,1 \%)$, Streptocus canis $(17,7 \%)$, Proteus mirabalis $(14,6 \%)$ and Staphylococcus aureus $(11,5 \%)$. Escherichia coli showed to be more sensible to gentamicin and chloranfenicol; ampiciline acted on wel against Streptococcus canis, while Proteus' samples had more sensibility to gentamicine and ampiciline; both chloranfenicol and gentamicine were efficient against Staphylococcus aureus.

\section{KEY-WORDS: Dog, Urinary Tract Infection, Microbiology.}

\section{REFERÊNCIAS BIBLIOGRÁFICAS}

BAUER, A.W., KIRBY, W.M.M., SHERRIS, J.C. et alli. Antibiotic susceptibility testing bya standardized single disc method. Amer. J. Clin. Path., v.45, p.493-496, 1966.

BROWN, S.A., BARSANT, J.A. Moléstias da Bexiga e Uretra. In : ETTINGER, S.J. Tratado de Medicina Interna Veterinária. São Paulo: MANOLE, 1992. p.2221.
BUSH, B.M. A review of the aetiology and consequences of urinary tract infections in the dog. British Veterinary Journal, v.132,n. 6 , p.632, 1976.

CHEW, D.J., DIBARTOLA, S.P. Diagnóstico e Fisiopatologia da Moléstia Renal. In : ETTINGER, S.J. Tratado de Medicina Interna Veterinária. São Paulo: MANOLE, 1992, p.1991. 
COTARD, J.P. L'Infection urinaire chez le chien et le chat et son traitment. Rec. Méd. Vét., v.166, n.3, p.291-303, 1990.

JANG, S.S., LING, G.V., YAMAMAMOTO, R. et alli. Mycoplasma as a cause of canine urinary tract infection. JAVMA, v.185, n.1, p.4547, 1984.

KRIEG, N.R., HOLT, J.G. Bergey's Manual of Systematic Bacteriology. 9.ed. Baltimore: Williams \& Wilkins, 1984. 1268p.

LING, G.V., RUBY, A.L. Chloramphenicol for oral treatment of canine urinary tract infections. JAVMA, v.172, n.8, p.914-916, 1978.

LING, G.V. Therapeutic strategies involving antimicrobial treatment of the canine urinary tract. JAVMA, v.185, p.1162, 1984.
LING, G.V., ROHRICH, P.J., RUBY, A.L. et al. Canine urinary tract infections : a comparison of in vitro susceptibility test results andresponse to oral therapy with ampicilin or with trimethoprim-sulfa. JAVMA, v.185, n.3, p.277-281, 1984.

OXENFORD, C.J., LOMAS, G.R., LOVE, D.N. Bacteriuria in the dog. J. Small Anim. Pract., v.25, p.83, 1984.

PERSON, J.M., QUINTIN-COLONNA, F., BOULOIS, H.J. L'Infection urinaire chez le chien et le chat. Rec. Méd. Vét., v.165, n.2, p.121$128,1989$.

ZAR, J.H. Biostatistical Analysis. Englewood Cliffs, Prentice-Hall International Editions, 1984. 718p. 